\title{
CHINESE PATERNALISTIC LEADERSHIP AND LEADERSHIP EFFECTIVENESS IN TEXTILE INDUSTRY
}

\author{
Hsien-Tang Tsai ${ }^{1}$, Tung-Ju Wu${ }^{1}$, Shang-Pao Yeh ${ }^{2 *}$ \\ 'Department of Business Management, National Sun Yat-Sen University, Kaohsiung, TAIWAN. \\ 2Department of Tourism, I-Shou University, Kaohsiung, TAIWAN. \\ *E-mail: shangpao@ms12.hinet.net
}

\begin{abstract}
:
The textile industry at one time, used to be one of the key industries in the economic development of Taiwan. Nevertheless, this labour- and time-intensive activity resulted in those employed in the industry not being able to devote adequate attention to both the family and business, that resulted in the enterprises being shipped out to other parts of labour-intensive Southeast Asia. This study aims to discuss the correlations between Chinese paternalistic leadership and organisational commitment, leadership effectiveness in the textile industry, and understanding the effects of supervisor-subordinate guanxi. Using quantitative questionnaire surveys, the supervisors and employees in 398 textile-related businesses in Taiwan, including 137 textile factories, 98 dyeing and finishing factories and 153 clothing factories, are studied. After applying hierarchical regression analysis to analysing the data, it is found that moral and benevolent leadership do not enforce as much obedience and performance as authoritarian leadership does. Instead, their loyalties are based on the "heart" of the employees to enhance their commitment to the organisation, by which the supervisor-subordinate guanxi could effectively adjust strong-arm leadership and the attitude of the employees. Therefore, it is suggested that Chinese supervisors should adopt benevolent leadership, maintain favourable guanxi with the employees, and improve the work atmosphere.
\end{abstract}

\section{Keywords:}

Chinese paternalistic leadership, organisational commitment, leadership effectiveness, supervisor-subordinate guanxi, textile industry

\section{Research background and motivation}

Being the largest foreign exchange earning industry that Taiwan once had, the textile industry used to make a huge contribution to the economy and social structure of Taiwan. Unfortunately, international developments, such as the cancellation of textile quotas, the formation of regional integration, the emergence of upcoming countries, and the change of production conditions in the domestic textile industry have caused the downward movement of industries. The end result is that the textile industry has gradually lost its ability to employ a sizeable portion of the population, thus giving the impression of approaching "sunset". However, the textile industry is not a dying industry because of the fierce competition that still exists. The global textile market grows at about 5-6 $\square$ annually, and the textile exports of Taiwan still present competition, in spite of the emergence of China and the Southeast Asian countries. Innovation is regarded as the optimal problem-solver, and the textile industry in Taiwan is estimated to grow to 0.1 trillion NT dollars in the next five years [1]. The textile industry in Taiwan is now facing a critical time that involves strategic transformation and resumption of the industry. Expertise in such a critical time can turn risks into opportunities, and see further improvements in a booming high-value industry that faces heavy competition.

Annually, the textile industry in Taiwan is quite capable of earning more than 10 billion US dollars during the peak period. Nevertheless, with the rapid development of electronics and the science and technology industry, and with the textile industry moving overseas for production, has resulted in the foreign exchange earnings through textiles falling behind the earnings of electronic products in 2004. There are currently about 5000 textile-related factories, and about 200000 employees, annually generating more than 0.45 trillion NT dollars in Taiwan. The textile industry still makes a substantial contribution to the economic development and local employment. Chinese leadership has always been considered to be a hard style of functioning [2]. There is very little affection between supervisors and subordinates. For this labour-intensive textile industry, this relationship is regarded as a major worry. It therefore becomes one of the reasons for this study that explores the employees' perception of the textile industry. Employees in the textile industry are extremely silent workers, thus, they are likely to be forgotten by society. Some couples even work in different shifts in the three-shift system, resulting in them hardly interacting with each other. Such a situation brings up another point of interest in this study about the work perception of basic-level labourers, and how the leadership style in the industry causes the employees to devote their time to the organisation over several decades, or even their entire lifetime. The correlations between leadership style, leadership effectiveness, and employee perceptions are largely involved in this study.

\section{Literature Review}

\section{Chinese Leadership and Leadership Effectiveness}

According to different theoretical structure and research subjects, the definition of organisational commitment is distinct 
[3], with the emphasis on the psychological process of an organisation, defined as an individual with a certain identity and investment in a specific organization. They explained it further from three different stages, including (1) believing in and accepting the organisational objective, value and management principle on the attitude, (2) willing to make efforts to achieve the organisational objective on behaviour, and (3) strongly eager to maintain the motivation of the member. It is seen that [4] regarded organisational commitment as the organisational identity of its members and the degree of investment which showed the characteristics of (1) willing to make an effort for the organisation, (2) presenting high belief and acceptance on organisational objective and value, and (3) strongly eager to retain a member of the organisation.

A lot of research and case studies on management showed that management in various regions, countries, or societies with distinct cultural values, required the coordination of the various cultures $[5,6]$. From the standpoint of the Chinese people, a lot of researchers discussed the organisational style and the high-level leadership in Chinese businesses, and indicated the clear and fresh characteristic of paternity, which not only presented a clear and strong authority, but also revealed the leadership of taking care of and being concerned about the subordinates and building up good examples. Such a leadership style was easily found in family owned businesses as well as public organisations, governmental institutes, and other types of organisations. The researchers called this kind of leadership "paternalistic leadership" [7,8]. Since such a leadership style often appears in Chinese organisations, it is named "Chinese paternalistic leadership" in this study. From past research $[7,9,10]$ indicated that paternalistic leadership covered benevolent, moral and authoritarian aspects. Such an obligation and beneficiary model commonly appeared between leaders and subordinates, and existed in both overseas Chinese family owned businesses, public businesses and governmental organisations in many Asian countries.

Porter and Smith [11] started the discussion on the psychological process of organisations, and defined organisational commitment as an individual with a certain identity and investment in a specific organisation. They further explained organizational commitment as (1) believing in and accepting the organisational objective, value and management principle on the attitude, (2) willing to make the extra effort to achieve the organisational objective on behaviour, and (3) strongly eager to retain the motivation of organisational membership [3], which were classified into value commitment, effort commitment and retention commitment. From many research results, [12] divided commitment into affective, continuance and normative.

Domestic research on leadership is mainly based on Western leadership styles. For instance, the leadership behaviours were divided into initiative and concern in Ohio State University, in which two leadership behaviours appeared to have significant correlations with organisational commitment. Regarding the correlations between Chinese paternalistic leadership and organisational commitment, benevolent and moral leadership showed remarkably positive correlations with organisational commitment, while authoritarian leadership appeared with negative correlations; administrators under balance oriented and benevolence-moral leadership presented higher organizational commitment than those under authoritarian oriented leadership. Accordingly, hypothesis 1 is proposed.

H1: Chinese paternalistic leadership and organizational commitment show positive correlations.

Fei [13] indicated in differential matrices that everyone would judge the status of others in an individual interpersonal relationship network according to the closeness of the blood relationship of others in order to identify the role relationship with others and only thereafter proceed with appropriate interaction. Chinese people particularly focus on the differences between people on their own side and outsiders. They would compare familiar ones with strangers, and that while the former are the ones on their own side, the latter are outsiders. Furthermore, in comparison with family, familiar ones are outsides, while family are the ones on their own. From the Chinese managers' perception and classification of employees, [2] considered differential matrices as the essence in the classification of Chinese business owners which contained guanxi, loyalty and talent. Guanxi refers to the blood or blood-like relationship between employees and the business owner; loyalty refers to the loyalty and unconditional obedience of employees towards the business owner; and talent referred to the competence of employees completing the objectives designated by the business owner.

Zenger [14] mentions that an organisation is generally judged by the effectiveness of the leadership and according to the performance of employees, as evaluated by the managers. However, relevant research also revealed that subordinates were capable of evaluating the leaders' performance, as the members of an organisation would have a specific style of appraisal when facing the leaders. The common indicators for measuring leadership effectiveness cover supervisor trust, team morale, team performance, satisfaction, organisational commitment and appraisal of leaders. Chinese paternalistic leadership, on the other hand, contains moral, benevolent and authoritarian features. Leadership could reflect the leadership effectiveness, as the followers expect to receive the leader's concern and care. In this case, moral and benevolent leadership, rather than authoritarian leadership, is preferred. Hypothesis 2 is therefore proposed.

H2: Chinese paternalistic leadership and leadership effectiveness reveal positive correlations

\section{Supervisor-Subordinate Guanxi}

In Chinese society, the connection among people is known as guanxi, a form of social connection, in which the establishment of relationship between two parties is based on mutual benefits [15]. Guanxi is the relationship among objects, forces and people [16], and a unique business practice in Pan-Asia $[16,17,18]$. In China, two most commonly used approaches are gift giving and banquets [19].

The differences between the Chinese guanxi and Western relationship are explained from four aspects as follows: (1) In 
morality, relationship in the West is regarded as an immoral deed; however, the Chinese suppose that using guanxi for generating obligations and only people unable to complete these obligations are considered unethical [20]. (2) In form, Western relationship is exact and open, while the Chinese guanxi is more personal and private [21]. (3) In structure, the Western relationship belongs to the organisational level, while the Chinese guanxi belongs to the individual level and is not solely about the business, but it also contains the social value, such as favourable exchange [19]. (4) In interaction, the Western relationship puts emphases on fairness, and yet, the Chinese guanxi emphasizes the double returns for the mercy received from others [21].

Aiming at Chinese-style management, the effects of Confucian culture on guanxi [22] and organisational guanxi [23] have been discussed in the past years. Guanxi exists uniquely in Chinese society, and the primary concept of guanxi has been proved in operation and management of Chinese society [24]; particularly, the effects on organisational members' attitudes, behaviours, and interaction could not be neglected $[16,25,26,27]$ (Luo, 1997). Thus, guanxi management in Chinese-style management is considerably important $[24,28]$. A lot of cross-cultural research findings showed that guanxi could affect all layers of Chinese society; especially, since guanxi was a critical factor in Chinese businesses.

Guanxi is not necessarily directly linked, in that the establishment might not actually be based on guanxi, but on mutual interests, and these are merely aids to establish an intimate relationship for final benefits. "Xin-ren" as one of the key factors in guanxi $[29,30,31]$ could connect people without relative guanxi or in distinct social stages through social interaction, so that the constant social interaction could result in better affection. Close guanxi could be developed and maintained by helping the others. As a result, reliability (Xin-ren) and human feelings (Ren-qing) are the key factors in maintaining guanxi.

Supervisor-subordinate guanxi, as a research point in an organisation [32], is generally used for discussing the morals, organisational fairness, and trust [33,34] (Ho \& KA, 2010). Past research indicates that better supervisor-subordinate guanxi could enhance affective commitment between subordinates and Chinese businesses [35]. Kiong and Kee [36] argued that mistakes could be easier forgiven and forgotten because of better guanxi. Hwang [19] pointed out that distinct guanxi would generate different differential correspondence and various resource (benefit) exchanges. Guanxi determines how to treat others and other relevant affairs in an interaction with others. Taormina and Gao [37] discovered the effects of guanxi behaviour, such as job satisfaction, mutual support among organisational employees, and self-attribution to success. The similar effects would appear in Taiwan, with the same cultural background, so that hypotheses 3 and 4 are proposed in this study.

H3: Supervisor-subordinate guanxi shows moderating effects on Chinese paternalistic leadership and organizational commitment.

H4: Supervisor-subordinate guanxi appears to have moderating effects on Chinese paternalistic leadership and leadership effectiveness.

\section{Research Design}

\section{Research model}

From the above literature review, the conceptual framework for this study is drawn (Figure 1).

\section{Measurement of research variable}

From [7], the Chinese paternalistic leadership scale contains 15 questions, which are divided into benevolent, moral, and authoritarian leadership. With a Likert 5-point scale, the Cronbach's a presented 0.863 . Reviewing [38,39], the leadership effectiveness scale included 10 questions, and the Cronbach's a showed 0.854 , with a Likert 5-point scale. Based on the 15 questions proposed by [40], the organisational commitment scale revealed the Cronbach's a 0.916, with a Likert 7-point scale. From a review of [32], the supervisorsubordinate guanxi scale covered five questions, and the Cronbach's $\alpha$ appeared 0.943 , with a Likert 7-point scale.

\section{Control variable}

Several research findings showed the notable effects of gender on paternalistic leadership where males presented

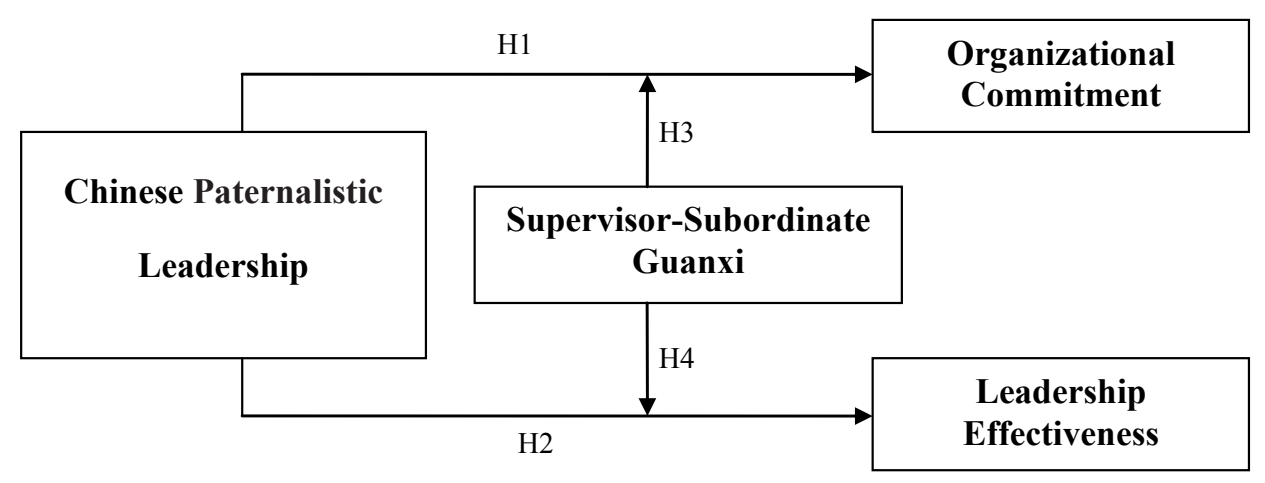

Figure 1. Research Model. 
a higher perception of paternalistic leadership than females did on moral leadership and benevolent leadership, but not on authoritarian leadership; and age revealed remarkable effects on all these types of leaderships. Nonetheless, some research results showed opposite findings, that age did not present significant effects on leadership. Gender and age were therefore considered as the control variables in this study [41].

\section{Research subject}

Supervisors and employees in the textile industry of Taiwan were selected as the research subjects in this study. Totally, 398 textile enterprises, including 137 textile factories, 98 dyeing and finishing factories and 153 clothing factories, were investigated. In terms of the questionnaire, Chinese paternalistic leadership scale was filled in by the supervisors, while organizational commitment, leadership effectiveness and supervisor-subordinate Guanxi scales were filled in by the subordinates.

\section{Research result and analysis}

The means, standard deviations and correlation coefficients among the focused variables are listed in Table 1.

Regression analysis of Chinese paternalistic leadership. organisational commitment and leadership effectiveness

With hierarchical regression analysis to test $\mathrm{H} 1$, Table 2, moral and benevolent leadership presented notably positive correlations $(\beta=0.295, p<0.001 ; \beta=0.116, p<0.05)$ with organisational commitment, while authoritarian presented remarkably negative correlations $(\beta=-0.232, p<0.001)$, that $\mathrm{H} 1$ was partially agreed. $\mathrm{H} 2$ was further tested, which showed that moral and benevolent leadership revealed remarkably positive correlations $(\beta=0.102, p<0.05 ; \beta=0.363, p<0.001)$ with leadership effectiveness, while authoritarian presented significantly negative correlations $(\beta=-0.187, p<0.01)$ that $\mathrm{H} 2$ was partially agreed.

\section{Moderating effects of supervisor-subordinate quanxi on the correlations between Chinese paternalistic leadership. organisational commitment and leadership effectiveness}

With hierarchical regression analysis to test $\mathrm{H} 3$, Table 3, supervisor-subordinate guanxi appeared as notably moderating effects on the positive correlations between moral leadership and organisational commitment $(\beta=0.388$, $p<0.001$ ), but insignificant effects on the notably positive correlations $(\beta=0.018, p>0.05)$ between benevolent leadership and organisational commitment, while the remarkably negative correlations between authoritarian leadership and leadership effectiveness approached positive tendency $(\beta=-0.041, p>0.05)$. Regarding the interactive items, the interaction between moral leadership and supervisor-subordinate guanxi, and between benevolent leadership and supervisor-subordinate guanxi, showed significantly positive correlations $(\beta=0.357, p<0.001$; $0.481, p<0.001$ ), while the interaction between authoritarian leadership and supervisor-subordinate guanxi appeared

Table 1. Means, standard deviations and correlations among variables.

\begin{tabular}{|c|c|c|c|c|c|c|c|c|}
\hline & M & SD & 1 & 2 & 3 & 4 & 5 & 6 \\
\hline 1. Benevolent & 3.54 & 0.57 & 1 & & & & & \\
\hline 2. Moral & 3.95 & 0.53 & $0.146^{*}$ & 1 & & & & \\
\hline 3. Authoritarian & 2.63 & 0.68 & $-0.315^{* *}$ & $-0.227^{* *}$ & 1 & & & \\
\hline 4. Employee Commitment & 3.66 & 0.41 & $0.322^{* *}$ & $0.191^{* *}$ & $-0.369^{* *}$ & 1 & & \\
\hline \multirow{2}{*}{$\begin{array}{l}\text { 5. Leadership Effectiveness } \\
\text { 6. Supervisor-Subordinate } \\
\text { Guanxi }\end{array}$} & 3.91 & 0.44 & $0.294^{* *}$ & $0.397^{\star \star}$ & $0.112^{*}$ & $0.143^{*}$ & 1 & \\
\hline & 4.12 & 0.39 & $0.135^{\star *}$ & $0.615^{\star \star}$ & $0.529^{* *}$ & $0.317^{* *}$ & $0.449^{* *}$ & 1 \\
\hline
\end{tabular}

Note. $N=398 ;{ }^{*} p<0.05 ;{ }^{* *} p<0.01$

Table 2. Results of hierarchical regression modelling

\begin{tabular}{|l|c|c|c|c|}
\hline & \multicolumn{3}{|c|}{ Dependent variables } \\
\hline & \multicolumn{2}{|c|}{ Employee commitment } & \multicolumn{2}{c|}{ Leadership effectiveness } \\
\cline { 2 - 5 } & M1 & M2 & M1 & $0.091^{*}$ \\
\hline Gender & -0.028 & -0.042 & $0.141^{* *}$ & 0.101 \\
\hline Age & $-0.408^{* *}$ & $-0.381^{* * *}$ & 0.012 & $0.102^{*}$ \\
\hline Menevolent & & $0.295^{* *}$ & & $0.363^{* * *}$ \\
\hline Authoritarian & & $0.116^{*}$ & & $-0.187^{* *}$ \\
\hline F values & & $-0.232^{* * *}$ & & 49.121 \\
\hline Adj $\mathbf{R}^{2}$ & 20.494 & 55.234 & 54.809 & 0.459 \\
\hline $\mathbf{R}^{2}$ & 0.164 & 0.442 & 0.352 & 0.107 \\
\hline
\end{tabular}

Note. $N=398 ;{ }^{*} p<0.05 ;{ }^{* *} p<0.01 ;{ }^{* * *} p<0.001$ 
Table 3. Results of hierarchical regression modelling.

\begin{tabular}{|c|c|c|c|c|c|c|}
\hline & \multicolumn{6}{|c|}{ Dependent variables } \\
\hline & \multicolumn{3}{|c|}{ Employee commitment } & \multicolumn{3}{|c|}{ Leadership effectiveness } \\
\hline & M1 & M2 & M3 & M1 & M2 & M3 \\
\hline Gender & -0.028 & -0.054 & -0.097 & $0.141^{* *}$ & 0.091 & 0.071 \\
\hline Age & $-0.408^{* * *}$ & $-0.372^{* * *}$ & $-0.322^{\star * \star}$ & 0.012 & 0.101 & 0.099 \\
\hline Benevolent & & $0.284^{* * *}$ & $0.388^{* * *}$ & & $0.211^{* * *}$ & $0.238^{* * *}$ \\
\hline Moral & & $0.079^{*}$ & 0.018 & & $0.274^{* * *}$ & $0.247^{* *}$ \\
\hline Authoritarian & & $-0.150^{\star \star \star}$ & -0.041 & & $-0.128^{\star *}$ & $-0.141^{*}$ \\
\hline Supervisor-subordinate Guanxi & & 0.201 & $0.281^{\star \star * *}$ & & $0.454^{* * *}$ & $0.427^{\star \star *}$ \\
\hline Benevolent*Guanxi & & & $0.357^{\star * *}$ & & & $0.282^{* * *}$ \\
\hline Moral*Guanxi & & & $0.481^{* * *}$ & & & $0.393^{* * *}$ \\
\hline Authoritarian*Guanxi & & & $-0.171^{* *}$ & & & $-0.199^{*}$ \\
\hline F values & 20.494 & 55.234 & 70.521 & 54.809 & 60.404 & 81.031 \\
\hline Adj $R^{2}$ & 0.164 & 0.488 & 0.601 & 0.352 & 0.545 & 0.636 \\
\hline$\Delta R^{2}$ & & 0.222 & 0.113 & & .196 & 0.091 \\
\hline
\end{tabular}

Note. $N=398 ;{ }^{*} p<0.05 ;{ }^{* *} p<0.01 ;{ }^{* \star *} p<0.001$

as notably negative correlations $(\beta=-0.171, p<0.01)$. H3, therefore, was partially agreed. It is worth mentioning that the better supervisor-subordinate guanxi could reduce the negative guanxi between authoritarian leadership and employee commitment.

In the test of $\mathrm{H} 4$, the moderator enhanced the positive correlations between moral leadership and leadership effectiveness, showing that supervisor-subordinate guanxi could enhance the positive correlations $(\beta=0.238, p<0.001)$ between moral leadership and leadership effectiveness, but reduce the positive correlations $(\beta=0.247, p<0.01$ ) between benevolent leadership and leadership effectiveness, while the negative correlations between authoritarian leadership and leadership effectiveness approached positive tendency $(\beta=-0.141, p<0.05)$. The interaction between moral leadership and supervisor-subordinate guanxi, and between benevolent leadership and supervisor-subordinate guanxi revealed remarkably positive correlations $(\beta=0.282$, $p<0.001 ; \beta=0.393, p<0.001$ ) with leadership effectiveness, while the interaction between authoritarian leadership and supervisor-subordinate guanxi appeared as notably negative correlations $\left(\beta=-0.199^{*}, p<0.05\right)$. $H 4$, therefore, was partially agreed. Similarly, the better supervisor-subordinate guanxi could reduce the negative guanxi between authoritarian leadership and leadership effectiveness.

\section{Conclusions and suggestions}

The research findings show negative correlations of authoritarian leadership and positive correlations of moral and benevolent leadership with organisational commitment and leadership effectiveness in textile industry. Moral leadership contains the behavioural qualities of making an example of oneself, and not acquiring private benefits, as well as the characteristics of providing fair treatment to all subordinates, undertaking responsibilities and being fair and honest. Benevolent leadership covers living concerns, work support, training, encouragement and the career plans of subordinates. Unlike authoritarian leadership that stresses on obedience and performance, moral and benevolent leadership start from the "heart". Such an organisational culture is common in Chinese businesses. In this case, supervisors in the textile industry correctly applying leadership styles and establishing favourable interaction and reliable guanxi with the subordinates, could induce the organisational commitment, enhance the leadership effectiveness and promote the work performance and service quality.

Law et al. [17] proposed supervisor-subordinate guanxi as a part of businesses. The empirical research on textilerelated enterprises in Taiwan also proves the critical role of supervisor-subordinate guanxi in Chinese businesses. This study further shows the negative effects of authoritarian leadership on employee commitment and perception. However, the better and closer supervisor-subordinate guanxi could reduce the negative guanxi. In other words, the Chinese guanxi, as an effective lubricant in businesses, could enhance the good perception of employees, and get rid of the harmful atmosphere in the organisation for a smooth operation of the business.

Supervisors in textile enterprises are suggested to pay attention to the work conditions of the employees, provide necessary emotional and business support, praise, and guidance. They should help prevent the employees who are lacking in experience, to adapting themselves to the workplace. The supervisors should also acquire personal orientation and satisfaction, offer educational training to help practice the professional knowledge acquired, and to solve problems at work, arrange appropriate work according to the individual's specialty, and promote a sense of achievement, so as to get a feeling of belonging and to merge one's identity with that of the organisation. 


\section{References}

[1] Economics Businesses Industries Changhua. 2008. http:// www2.chcg.gov.tw

[2] Cheng, B. S. 1995. Differential mode of the association and Chinese organizational behavior. Indigenous Psychological Research in Chinese Societies, 3: 142-219. (in Chinese)

[3] Poter, L. W., Steers, R. M., Mowday, R. T., \& Boulian, P. V. 1974. Organizational commitment, job satisfaction, and tournover among psychiatric technicians. Journal of Applied Psychology, 59(5): 603-609.

[4] Morrow, P. C. 1983. Concept redundancy in organizational research: The case of work commitment. Academy of Management Review, 8: 486-500.

[5] Hofstede, G. H. 1980. Culture's consequences: International differences in work-related values. Beverly Hill, CA: Sage.

[6] Hofstede, G. H., \& Bond, M. H. 1988. The Confucius connection: From cultural roots to economic growth. Organizational Dynamics, 16(4): 4-21.

[7] Cheng, B. S., Chou, L. F., \& Farh, J. L. 2000. A triad model of paternalistic leadership: The constructs and measurement. Indigenous Psychological Research in Chinese Societies, 14: 3-64. (in Chinese)

[8] Pye, L. W. 1985. Asia power and politics. Cambridge, MA: Harvard University Press.

[9] Silin, R. H. 1976. Leadership and value: The organization of large-scale Taiwan enterprises. Cambridge, MA: Harvard University Press.

[10] Westwood, R. 1997. Harmony and patriarchy: The cultural basis for 'paternalistic headship' among the overseas Chinese. Organization Studies, 18(3): 445-480.

[11] Porter, L. W., \& Smith, F. J. 1970. The etiology of organizational commitment. Unpublished paper. University of California, Irvine.

[12] Meyer, J. P., Allen, N. J., \& Smith, C. A. 1993. Commitment to organizations and occupations: Extension and test of a three-component conceptualization. Journal of Applied Psychology, 78(4): 538-551.

[13] Fei, H. T. 1948. Peasant Life in China. London: Routledge \& Kegen.

[14] Zenger, J. H., \& Folkman, J. 2003. The handbook for leaders: 24 lessons for extraordinary leadership. New York: McGraw-Hill.

[15] Xin, K.R., \& Pearce, J, L. 1996. Guanxi: connections as substitutes for formal institutional support. Academy of Management Journal, 39(6): 1641-1658.

[16] Yang, M. M. 1994. Gifts, favors and banquets: The art of social relationships in China. Ithaca, NY: Cornell University Press.

[17] Hall, R. H., \& Xu, W. 1990. Run silent, run deep-cultural influences on organizations in the Far East. Organization Studies, 11: 569-576.

[18] Lockett, M. 1988. Culture and problems of Chinese management. Organization Studies, 9: 475-496.

[19] Hwang, K. K. 1987. Face and favor: the Chinese power game. American Journal of Sociology, 92(4): 944-974.

[20] Vanhonacker, W. R. 2004. Guanxi networks in China. China Business Review, 31(3): 48-53.
[21] Hackley, C. A. \& Dong, Q. 2001. American public relations networking encounters China's guanxi. Public Relations Quarterly, 46(2): 16-20.

[22] Tsui, A. S., \& Farh, J. L. 1997. Where guanxi matters: relational demography and guanxi in the Chinese context. Work and Occupations, 24(1): 56-79.

[23] Zhang, Y., \& Zhang, Z. 2006. Guanxi and organizational dynamics in China: A Link between individual and organizational levels. Journal of Business Ethics, 67(4): 375-392.

[24] Tsai, H. T., Yeh, S. P., \& Wu, T. J. 2011. The use of governmental-firm guanxi under different market conditions for Taiwanese hospitality firms invested in China. Actual Problems of Economics, 12(2): 4-11.

[25] Farh, J. L., Tsui, A., Xin, K., \& Cheng, B. S. 1998. The influence of relational demography and guanxi: the Chinese case. Organization Science, 9(4): 471-489.

[26] Park, S. H., \& Luo, Y. 2001. Guanxi and organizational dynamics: organizational networking in Chinese firms. Strategic Management Journal, 22(5): 455-477.

[27] Warner, R. S. 1993. Work in progress toward a new paradigm for the sociological study of religion in the United States. American Journal of Sociology, 98(5): 1044-1093.

[28] Hwang, K. K. 2009. Confucian relationalism: Philosophical reflections, theoretical construction, and empirical research. Taipei: Psychological Publishers. (in Chinese)

[29] Lee, D. J., Pae, J. H., \& Wong, Y. H. 2001. A model of close business relationships in China (guanxi). European Journal of Marketing, 35(1/2): 51-69.

[30] Lee, D. Y., \& Dawes, P. L. 2005. Guanxi, trust, and longterm orientation in Chinese business markets. Journal of International Marketing, 13(2): 28-43.

[31] Zhuang, G., Xi, Y. \& Tsang, S. L. 2010. Power, conflict, and cooperation: The impact of guanxi in Chinese marketing channels. Industrial Marketing Management, 39: 137-149.

[32] Law, K. S., Wong, C. S., Wang, D., \& Wan, U. 2000. Effect of supervisor-subordinate guanxi on supervisory decisions in China: an empirical investigation. International Journal of Human Resource Management, 11(4): 751-765.

[33] Han, Y., \& Altman, Y. 2009. Supervisor and subordinate Guanxi: a grounded investigation in the People's Republic of China. Journal of Business Ethics, 88(1): 91-104.

[34] Jiang, X., Chen, C. C., \& Shi, K. 2012. Favor in exchange for trust? The role of subordinates'attribution of supervisory favors. Asia Pacific Journal of Management. doi:10.1007/ s10490-011-9256-6.

[35] He, Y., Laib, K., \& Lu, Y. 2011. Linking organizational support to employee commitment: evidence from hotel industry of China. The International Journal of Human Resource Management, 22(1): 197-217.

[36] Kiong, T. C., \& Kee, Y. P. 1998. Guanxi, xinyong and Chinese business networks. The British Journal of Sociology, 49(1): 75-96.

[37] Taormina, R. J., \& Gao, J. H. 2010. A research model for Guanxi behavior: Antecedents, measures, and outcomes of Chinese social networking. Social Science Research, 39(6): 1195-1212.

[38] Tyler, T. R. 1994. Psychological models of the justice motive. Journal of Personality and Social Psychology, 67(5): 850-863 
[39] Wayne, S. J., \& Ferris, G. R. 1990. Influence tactics, affect, and exchange quality in supervisor-subordinate interaction: A laboratory experiment and field study. Journal of Applied Psychology, 75(5): 487-499.

[40] Mowday, R. T., Porter, L. W., \& Steers, R. M. 1982. Employee-organization linkages The psychology of commitment, absenteeism, and turnover. New York: Academic Press.

[41] Cheng, B. S., Chou, L. F., Wu, T. Y., Huang, M. P., \& Farh, J. L. 2004. Paternalistic leadership and subordinate responses: Establishing a leadership model in Chinese organizations. Asian Journal of Social Psychology, 7(1): 89-117. 